\title{
Estrutura formal e semântica do argumento autogenealógico em Nietzsche
}

\author{
Formal and semantic structure of the self-genealogical argument \\ in Nietzsche
}

\author{
Jorge Luiz Viesenteiner \\ jvies@uol.com.br \\ (Universidade Federal do Espírito Santo, Espírito Santo, Brasil)
}

\begin{abstract}
Resumo: 0 objetivo do texto é analisar a estrutura formal e semântica daquilo que denomino de argumento autogenealógico em Nietzsche, culminando com um breve esboço das suas formas de comunicabilidade. Do ponto de vista formal, trata-se de compreender o conceito de genealogia em seu registro crítico, em estreita conexão com uma práxis interrogativa fomentadora de um distanciamento metódico; do ponto de vista semântico, trata-se de compreender que aquilo que era elaborado por Nietzsche até 1887 em Para genealogia da moral com vistas à cultura, realiza-se nos textos de $1888 \mathrm{com}$ vistas a si mesmo. Finalizo com um breve e plausível sentido de autoencenação, na medida em que Nietzsche transforma a si mesmo em figura de pensamento, especialmente em Ecce homo.
\end{abstract}

Palavras-chave:genealogia; autogenealogia; crítica; práxis interrogativa; autoencenação

\begin{abstract}
This paper aims to analyze the formal and semantic structure of what I call as self-genealogical argument in Nietzsche, culminating with a brief outline of its form of communicability. From a formal point of view, the concept of genealogy must be understood from its critical register, in necessary connection to an interrogative praxis feeder of a methodical distancing; from a semantic point of view, my hypothesis is that precisely that which was elaborated by Nietzsche until 1887 in Zur Genealogie der Moral, thought especially in the view of culture, is realized in the 1888 texts, now in the view of himself. I finish with a brief and plausible sense of self-staging, insofar as Nietzsche converts himself into an argumentative instance, especially in Ecce homo.
\end{abstract}

Keywords: genealogy; self-genealogy; interrogative praxis; self-staging

DOI: http://dx.doi.org/10.11606/issn.2318-9800.v20i2p105-119

\section{Introdução ${ }^{1}$}

Nietzsche nunca empregou o termo autogenealogia, uma vez que seu escrito polêmico caracterizava uma práxis genealógica com vistas à moralidade. Referir-se então à autogenealogia implica justificar, em primeiro lugar, o movimento conceitual que autorize, intratextualmente, a passagem de uma genealogia da moral para uma práxis autogenealógica de forma plausível. Nomeio esse primeiro movimento de estrutura formal do argumento autogenealógico. Minha hipótese nesse primeiro movimento do texto consiste em compreender o conceito de genealogia em seu

1 Esta pesquisa é financiada pelo CNPq, contemplada com bolsa de pesquisa por meio do Edital Universal MCTI/CNPq 14/2014, com vigência até 2017. 
registro crítico, em necessária conexão com uma práxis interrogativa fomentadora de um distanciamento metódico, cuja correlação amplia a margem de atuação do conceito de genealogia, autorizando seu emprego não apenas à moral, mas também em relação à tradição filosófica da verdade e inclusive em relação à autocompreensão genealógica de si mesmo. Em segundo lugar, trata-se também de explicar as estruturas teóricas que caracterizam o significado de uma práxis autogenealógica, mas agora em se tratando de conteúdo semântico dessa práxis, justificando tanto as correlações de sentido entre genealogia e autogenealogia, bem como a dupla caracterização da própria práxis autogenealógica. Nomeio esse segundo movimento de estrutura semântica do argumento autogenealógico. Minha hipótese é que precisamente aquilo que era elaborado por Nietzsche até 1887 em Para genealogia da moral, especialmente pensado com vistas à cultura, é efetivado nos textos de 1888 , agora com vistas a si mesmo. Ou seja, as reflexões sobre os dramas do destino da alma expressos com a pergunta "O que significam ideais ascéticos?", analisados em interlocução com a arte, filosofia, ciência e religião, são desdobrados individualmente em 1888 no próprio Nietzsche, como práxis de diferenciação em relação a cada um desses domínios da cultura, em seus respectivos livros: arte em 0 caso Wagner, filosofia e ciência no Crepúsculo dos ídolos e religião em $O$ anticristo.

Esse movimento argumentativo culmina justamente em Ecce homo, na medida em que Nietzsche converte a si mesmo em instância argumentativa, cujo procedimento é realizado por meio de uma autoencenação filosófica. Trata-se da estratégia argumentativa em que o autor Nietzsche narra um personagem que, para além de qualquer justificação ou explicação biográfica sobre tal personagem, prefere mostrá-lo aos seus interlocutores, apontando: Ecce homo. A estratégia de autoencenação filosófica caracteriza a filosofia de Nietzsche, por fim, como um pensamento que só fecha seu ciclo com a necessária presença do leitor.

\section{Estrutura formal do argumento autogenealógico: crítica e práxis interrogativa}

Para genealogia da moral (GM)², de 1887, tem de ser lida, contextualmente, como "complemento e elucidação" de Para além de bem e mal (ABM), tal como Nietzsche registra no verso do frontispício do livro ${ }^{3}$. Nesse caso, é possível compreender a argumentação que vai de uma "tipologia da moral", tal como Nietzsche escreve

2 As obras de Nietzsche são citadas conforme a edição crítica: NIETZSCHE, F. Sämtliche Werke. Kritische Studienausgabe in 15 Bänden. (KSA) Hrsg. Giorgio Colli und Mazzino Montinari. Berlin/ New York: DTV \& Walter de Gruyter, 1999. Utilizo as seguintes referências já consolidadas para os textos de Nietzsche, aos livros que cito: Para as referências de obras enviadas para publicação de Nietzsche, segue-se a abreviação do livro (GC: A gaia ciência; ABM: Para além de bem e mal; GM: Para genealogia da moral; CW: $O$ caso Wagner; $\mathrm{EH}$ : Ecce homo), número do aforismo e referência nas obras completas KSA, com seu respectivo volume e número de página (p.ex., ABM 257; KSA 5 , p.205; EH, Crepúsculo dos ídolos 2; KSA 6, p.355, etc.).Todas as traduções são de minha própria autoria.

3 KSA 14, p.377. 
no aforismo 186 que abre o capítulo de ABM intitulado "Contribuição à história natural da moral", até o programa teórico de uma "efetiva história da moral" em GM, precisamente para percorrer a "moral efetivamente vivenciada - com novas perguntas e igualmente com novos olhos" ". Um registro teórico nesse percurso de uma "tipologia" para uma "genealogia da moral" deixa-se caracterizar pelo sentido de genealogia como crítica que, grosso modo, dirige sua suspeita contra aquelas morais “que se voltam para 'todos', pois generalizam onde não é lícito ser generalizado - todas falando incondicionalmente, tomando-se a si incondicionalmente"5. A deshistoricização da moral atinge seu ponto de culminância, escreve Nietzsche em $A$ gaia ciência (GC), ali onde a moral mesma não é mais vista "como problema", mas antes, com os filósofos todos exigindo apenas a "fundamentação da moral", apesar da moral mesma, porém, vigorasse como "dada"7, isto é, sedimentada, cristalizada e convertida em autoevidente no interior de uma cultura. O programa da genealogia como "crítica", nesse caso, na medida em que se pergunta pelo "valor desses valores", consiste precisamente em "pôr em questão" aqueles valores que eram tidos como

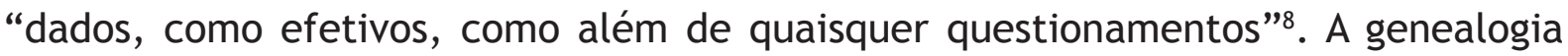
crítica radicaliza os esforços de uma mera "Entstehungsgeschichte" [história de surgimento], ${ }^{9}$ visto que uma "crítica" pressupõe pôr em evidência e destacar o que se tornou demasiado invisível e inquestionável em uma estrutura, inclusive além de qualquer questionamento no interior da própria história de surgimento dos valores. A historicização de valores é um importante instrumento cuja função é operar um distanciamento metódico das determinações dominantes e hegemônicas da época, mas que é radicalizado quando o programa crítico põe em evidência suas próprias estruturas que se tornaram demasiadas autoevidentes no interior desse processo.

Ao programa crítico da genealogia tem de se vincular um aspecto decisivo à estrutura formal do argumento autogenealógico, a saber, a práxis interrogativa necessariamente constitutiva às implosões das autoevidências. Essa necessária associação nos permite ampliar as margens de atuação do conceito de genealogia, sobretudo em seu uso para além de uma genealogia direcionada à moral. Tão logo operamos com as variáveis "programa crítico" e "práxis interrogativa", conseguimos deslocar a economia da argumentação para todos os domínios da cultura, resguardando os mesmos objetivos do

4 GM, Prólogo 7; KSA 5, p.254.

5 ABM 198; KSA 5, p.118.

6 GC 345; KSA 3, p.577.

7 ABM 186; KSA 5, p.105s.

8 GM Prólogo 6; KSA 5, p.253.

9 GC 345; KSA 3, p.578. Cf. STEGMAIER, W. Nietzsches „Genealogie der Moral“. Darmstadt: WGB, 1994, p.66: "Genealogia como crítica ao invés de história é a crítica das aparentes autoevidências da moral, por meio de um contínuo esboço hipotético sobre sua proveniência". 
programa genealógico/crítico de destacar ou pôr a nu as inquestionabilidades.

Se Nietzsche grifa o termo "crítica" no aforismo 6 do Prólogo de GM, é igualmente nesse mesmo aforismo que reconhecemos sua insistência em relação a uma práxis interrogativa. 0 aforismo traz três ocorrências do radical Fragen - "ein Fragezeichen”, “in Fragezustellen”, "In-Frage-Stellung” - bem como articulado com terminologias como "desconfiança" [Misstrauen], "suspeita" [Argwohn], dúvida e hesitação, etc. Contextualmente, o aforismo 345 de $A$ gaia ciência (GC), cujo livro V é contemporâneo ao programa genealógico de 1887, traz como título "Moral como problema" e instrumentaliza precisamente a práxis interrogativa para caracterizar a diferença entre "crítica" e "história de surgimento": "ninguém até agora, pois, testou o valor daquele mais famoso medicamento, a denominada moral: para isso se exige, acima de tudo, que algum dia - se a coloque em interrogação. Pois bem! Justamente esse é o nosso trabalho.-". ${ }^{10} 0$ distanciamento metódico capaz de evidenciar as cristalizações morais tem como ferramenta constitutivamente necessária a práxis interrogativa, não apenas para enxergar a "moral como problema", mas ao lado de tal práxis, para ampliar o conceito de genealogia a outros domínios da cultura e pôr em marcha o mesmo programa de des-velamento de sedimentações. ${ }^{11}$

A partir das variáveis "crítica" e "práxis interrogativa", gostaria de propor um movimento argumentativo que justifica o emprego da palavra autogenealogia, notadamente na constelação de três aforismos decisivos: o aforismo 6 do Prólogo de GM, o aforismo 1 de ABM e o 346 de GC. Os três aforismos pertencem, por um lado, ao mesmo contexto genético de 1886/87 e reproduzem o exercício de pôr a nu as autoevidências no interior de um processo e, por outro lado, todos trazem igualmente a preocupação com o próprio homem, ou ainda, com a pergunta pela compreensão genealógica sobre o homem.

0 aforismo 1 de $A B M$ está inserido no capítulo intitulado "Dos preconceitos dos filósofos", provavelmente um dos mais geniais capítulos escritos por Nietzsche. ${ }^{12}$ Todo aforismo, curiosamente, é redigido por meio de uma práxis interrogativa - doze interrogações no total - que, nesse caso, é dirigida contra aquele que certamente figura entre os mais cristalizados e autoevidentes conceitos da tradição filosófica, a saber, o conceito de verdade que, como o título indica, configura-se como mais um

10 GC 345; KSA 3, p.579.

11 Quero enfatizar que a noção de genealogia como programa crítico, além da interpretação de W. Stegmaier, é encontrada também em KAULBACH, F. Nietzsches Ideeeiner Experimentalphilosophie. Köhl/Wien: Böhlau, 1980, especialmente pp.82-116 e TONGEREN, P. A moral da crítica de Nietzsche à moral. Curitiba: Champagnat, 2012, especialmente pp.99-105 e pp.119-122.

12 A propósito de uma precisa análise desse primeiro capítulo de Para além de bem e mal, cf. LOSSI, A. Philosophie als Selbstgestaltung? Umwertung und Selbstverständnis im Ausgang von Nietzsches von den ,Vorurtheilen der Philosophen' in Jenseits von Gut und Böse“. In: BORN, M.;PICHLER, A. (Hrsg.). Texturen des Denkens. Nietzsches Inszenierung der Philosophie in Jenseits von Gut und Böse. Berlin/Boston: Walter de Gruyter, 2013, pp.107-122. 
dos “preconceitos" dos filósofos. A práxis crítico/interrogativa de Nietzsche consiste em tornar claras as relações, mecanismos e processos que terminaram em converter o conceito de verdade em "preconceito", ou seja, em um conceito que esteve além de qualquer questionamento e, portanto, autoevidente no interior da filosofia.

Nietzsche inicia o aforismo com a expressão "vontade de verdade", imediatamente articulada com aquilo que é mais característico na sua "história": "que tipo de questões essa vontade de verdade já nos apresentou! Todas questões estranhas, sombrias, questionáveis questões!". ${ }^{13}$ Não nos interessa aqui a discussão do significado da terminologia "vontade de verdade", mas sim enfatizar três aspectos decisivos na economia da minha argumentação. Em primeiro lugar, registro a correspondência dos projetos teóricos, pois se em GM se trata de evidenciar as cristalizações morais com a pergunta pelo "valor dos valores", em ABM se trata da pergunta pelo "valor da vontade de verdade". Apesar de os objetos de investigações serem díspares - a verdade em $A B M$ e a moral em GM - as variáveis crítica e a práxis interrogativa são semelhantes. Em segundo lugar, descobrir como a verdade se cristalizou como preconceito filosófico pressupõe pôr em questão a própria pergunta pela verdade, isto é, não mais a pergunta sobre o que é a verdade, mas sim "quem é aqui que realmente nos coloca perguntas?", escreve Nietzsche, ou “O que em nós quer realmente 'a verdade'?" Esse deslocamento interrogativo consiste em questionar o próprio lugar de onde o filósofo poderia se perguntar pela verdade, evitando assim reivindicar um suposto espaço transcendental por meio do qual Nietzsche enunciaria qualquer discurso sobre a verdade. Acima de tudo, trata-se de levar ao limite a própria pergunta que se tornou clássica na filosofia, forçando a práxis interrogativa agora contra si mesmo: “O que em nós quer realmente 'a verdade’?”. Por fim, o extremo das variáveis "crítica" e "práxis interrogativa" é atingido quando não se sabe mais os limites entre quem é "Édipo e quem é Esfinge”, uma interessantíssima figura de pensamento por meio da qual Nietzsche instrumentaliza essa radicalidade crítica. Nietzsche escreve: "O problema do valor da verdade surgiu diante de nós, - ou formos nós que aparecemos diante do problema? Quem de nós aqui é Édipo? Quem é Esfinge? Perguntas e interrogações parecem marcar um encontro." Como se sabe, a enigmática pergunta da Esfinge é justamente a pergunta pelo homem. Nesse caso, Édipo diante da Esfinge é, no fundo, Édipo diante de si mesmo respondendo a pergunta pelo próprio homem que, na encenação construída por Nietzsche, significa igualmente Édipo se perguntando por si mesmo, especialmente ao forçar as interrogações contra ele próprio, a fim de descobrir "quem" e "o que" efetivamente põe perguntas ou quer a verdade. Autoatribuindo-se o primeiro a ter "ousado" colocar o problema do valor da verdade, Nietzsche não quer mais encontrar o fundamento da verdade, ou os critérios do verdadeiro, ou mesmo como é possível

13 ABM 1; KSA 5, p.15. 
um acesso privilegiado à verdade; em todos esses casos, a verdade é tida como dada, como inquestionável. Antes disso, Nietzsche desdobra em ABM o programa crítico e a práxis interrogativa direcionada agora não contra a moral, mas contra a própria verdade, expondo seus limites e revelando-a um "preconceito", como intitula o capítulo. Como se vê, a interconexão das variáveis teóricas "crítica" e "práxis interrogativa" amplia as possibilidades de empregar o movimento argumentativo de Nietzsche na Genealogia para outros tantos domínios de crítica à cultura, como no caso da verdade como preconceito cristalizado no interior da filosofia já em ABM.

A radicalidade de ambas as variáveis, no entanto, extrai suas últimas consequências no instante em que Nietzsche encena filosoficamente o movimento de autorreflexividade da sua própria práxis interrogativa, agora para imprimir o distanciamento metódico em relação a si mesmo, no rigoroso sentido de se perguntar se ele próprio, como filósofo, não carregaria igualmente as mesmas cristalizações teóricas que quer encontrar em sistemas morais ou tradições filosóficas. Contextualmente, trata-se de mobilizar o aforismo 346 de A gaia ciência e que recebe como título precisamente "Nossa interrogação". Esse aforismo arremata a estrutura formal do argumento autogenealógico, porque consiste em reconhecer que a dinâmica das variáveis "crítica" e "práxis interrogativa" não pode deixar de se direcionar, por dever de honestidade, justamente contra aquele que as instrumentaliza contra filósofos, tradições filosóficas, sistemas morais ou culturas. Isso significa que agora é o próprio Nietzsche que, autoencenando-se como "ateu, descrente e imoralista" em uma só pessoa, tem de se reconhecer inserido no mesmo processo contra o qual ele interroga. Ressalto que a economia do programa crítico da genealogia, quando associada à práxis interrogativa, deixa-se desdobrar inclusive nos casos em que Nietzsche pretende colocar-se a si mesmo no contexto questionado, não apenas como programa crítico, mas agora como programa autocrítico!14

Chamo atenção a dois aspectos logo no início do aforismo para meu argumento: por um lado, o aforismo começa com uma interrogação, que por sua vez é inserida imediatamente depois que Nietzsche escreve sobre o programa crítico da genealogia, no aforismo 345 de $A$ gaia ciência, de modo que ambos os textos têm de ser lidos contextualmente. Depois de registrar o que Nietzsche denomina "nosso trabalho", isto é, questionar o valor do "mais famoso medicamento, a denominada moral", a fim de ver a "moral como problema", o aforismo 346 é inaugurado novamente com uma interrogação sobre a compreensão desse projeto, direcionada performaticamente aos leitores - "Mas vocês não entendem isso?"15; por outro lado, os três textos que analiso inserem no centro das preocupações a pergunta pela compreensão do que é o homem.

14 Para uma análise detalhada desse aforismo 346, cf. STEGMAIER, W. Nietzsches Befreiung der Philosophie. Berlin/Boston: Walter de Gruyter, 2012, especialmente as pp.163-174 sobre o aforismo 345 e pp.193-208 sobre o aforismo 346 de A gaia ciência.

15 GC 346; KSA 3, p. 579. 
0 aforismo 346 de GC alude à pergunta pelo homem já nas primeiras linhas: "quem somos nós?", conectando-se estreitamente com os dois textos anteriores, na medida em que o início da Genealogia é uma pergunta pelo entendimento sobre o homem "Nós nos somos desconhecidos, nós homens do conhecimento, nós nos desconhecemos de nós mesmos"16 -, e o texto de ABM constrói a figura de pensamento entre Édipo e a Esfinge para indicar, como analisei, que Édipo diante da Esfinge é Édipo diante da pergunta sobre si mesmo. Assim, a tríade de textos que analiso não apenas se complementam em se tratando das variáveis "crítica" e "práxis interrogativa", como também carregam como tema nuclear a preocupação com a compreensão do homem.

O final do aforismo, porém, destaca a preocupação de Nietzsche em direcionar, estrategicamente, a práxis interrogativa contra si mesmo, em um movimento autocrítico, tornando ainda mais claro o sentido do título do aforismo, "Nossa interrogação". No aforismo 346, o foco de debate é o niilismo que, porém, é instrumentalizado por Nietzsche como lente de aumento para a efetiva preocupação do texto, a saber, que o diagnóstico do niilismo é, simultaneamente, uma suspeita contra os diagnosticadores do próprio niilismo. A premissa do argumento é que usualmente $o$ homem categorizou o mundo "segundo uma necessidade", interpretando-o "por muito tempo de modo falso e mentiroso", até descobrir, finalmente, "que o mundo não possui o valor que acreditávamos", bem como paradoxalmente, um diagnóstico que exprime "o que há de mais seguro de que nossa desconfiança enfim se apoderou"17. 0 juízo pessimista que reza que esse mundo já não vale mais nada, nesse caso, tem de ser uma suspeita contra nós mesmos, na medida em que fomos nós que o interpretamos e doamos sentido para poder nos sentir "em casa com nossas venerações". É forçoso se perguntar, portanto, se o juízo pessimista não é, simultaneamente, o diagnóstico de que o próprio homem já não é mais "medida de todas as coisas", evidenciando aquilo que estava inquestionado no próprio juízo pessimista. Ora, se fomos nós mesmos que, na condição de "medida de todas as coisas", interpretamos e valoramos o mundo doando sentido a ele, diagnosticá-lo como sem valor implica, ao mesmo tempo, em reconhecer que nós mesmos já não possuímos qualquer sentido ou valor. 0 final do aforismo é construído igualmente por meio de uma série de interrogações que têm a função de forçar que aqueles que se interrogam sobre o valor do mundo, precisam também fazer a pergunta sobre o valor de si mesmos, autorreflexivamente, questionando o próprio lugar de onde emitem o juízo pessimista:

Não caímos justamente com isso na suspeita de um antagonismo, um antagonismo do mundo no qual estávamos até agora em casa com nossas venerações (...), e um outro mundo que somos nós mesmos: numa inexorável, fundamental e profunda desconfiança sobre nós mesmos (...) que cada vez pior nos toma de

16 GM Prólogo 1, KSA, p.247.

17 GC 346; KSA 3, p.580. 
assalto e facilmente poderia colocar as gerações vindouras diante do terrivel ouou: "ou suprime vossas venerações ou - vocês mesmos!" O último seria niilismo; mas o primeiro não seria também - o niilismo? - Essa é a nossa interrogação.

A estratégia argumentativa de Nietzsche é a pergunta por algo que está para além de qualquer questionamento no juízo pessimista sobre o mundo, a saber, se não é o homem mesmo, e inclusive o próprio Nietzsche como médico da cultura que diagnostica o niilismo, que no fundo tem seu valor desvalorizado e, por isso, já não consegue mais ser a "medida de todas as coisas", como Nietzsche escreve.Trata-se de ter que interrogar agora contra si mesmo, como movimento autocrítico, o que está cristalizado e não problematizado no juízo pessimista. Ajuizar sobre o fato de que o mundo não tem qualquer valor, portanto, é no mínimo uma "suspeita sobre nós mesmos". O movimento autocrítico, porém, só é compreendido se reconhecemos que Nietzsche tem de enxergar a si mesmo inserido no processo que é por ele analisado. $\mathrm{A}$ "nossa interrogação" que intitula o aforismo é, no fundo, autointerrogação direcionada contra o próprio lugar de onde o juízo pessimista sobre o mundo é enunciado. ${ }^{18}$

O aforismo 346 de $A$ gaia ciência, em suma, carrega o ponto de culminância de uma equação que conjuga as variáveis "crítica” e “práxis interrogativa”, na medida em que o mesmo movimento argumentativo do programa genealógico pode ser deslocado para além do horizonte moral, nesse caso, direcionado ao preconceito da verdade ou mesmo como movimento autocrítico de compreensão das próprias condições culturais. 0 aforismo 346 radicaliza a equação genealógica, permitindo-nos compreendê-la como válida igualmente no interior de uma práxis autogenealógica. Por isso, embora Nietzsche não tenha empregado o termo autogenealogia, se seguirmos o movimento conceitual que subjaz ao programa teórico da genealogia, tal como sugiro, ampliamos esse movimento não apenas no âmbito da moral, mas inclusive em relação a si próprio como autogenealogia.

\section{Estrutura semântica do argumento autogenealógico: da crítica à cultura à práxis autogenealógica}

É preciso justificar não apenas formalmente as correlações da economia argumentativa entre genealogia e autogenealogia, mas sobretudo em que medida as conexões relativas ao aspecto semântico do argumento autogenealógico ainda mantém sintonia com o programa genealógico de 1887. Minha hipótese é que aquilo que Nietzsche operava com vistas a uma crítica à cultura por meio da pergunta pelo significado dos ideais ascéticos em GM, estrutura-se nos textos de 1888 com

180 aforismo também termina com uma interrogação, ou seja, uma estratégia performativa que força o próprio leitor a se reconhecer no mesmo processo que é criticado, objetivando sua própria transformação. Sobre isso, cf. SAAR, M. Genealogie als Kritik. Geschichte und Theorie des Subjekts nach Nietzsche und Foucault. Frankfurt/New York: Campus Verlag, 2007. 
vistas para si mesmo. O programa genealógico de 1887 em GM, especialmente na terceira dissertação, direciona-se às principais estruturas da cultura: arte, filosofia, ciência, religião e moral. Contextualmente, essas estruturas culturais correspondem, curiosamente, a cada um dos livros que Nietzsche escreve em 1888: O caso Wagner (arte), Crepúsculo dos ídolos (filosofia e ciência), $O$ anticristo (religião), além de mostrar a si mesmo como filósofo Nietzsche, convertendo a si mesmo na figura de pensamento "Nietzsche", em Ecce homo. ${ }^{19}$

A investigação feita por Nietzsche depois da pergunta que intitula a terceira dissertação de Para genealogia da moral, a saber, “O que significam ideais ascéticos?”, é sistematicamente interpretada em cada um dos domínios da cultura. Nos aforismos 2 a 5 da terceira dissertação, a esfera da arte é problematizada e Wagner é o principal interlocutor; entre os aforismos 6 e 10, a investigação sobre os dramas do destino da alma se volta à filosofia; nos aforismos 11 a 22, a análise é na esfera da religião e da moral, e tem como lente de aumento e interlocução o papel do sacerdote; a ciência também aparece, nos aforismos 23 a 26, como a forma moderna que igualmente busca respostas ao drama do destino da alma. ${ }^{20}$ Assim, arte, filosofia, religião, moral e ciência são os domínios por meio dos quais Nietzsche emprega sua práxis genealógica num horizonte cultural. Esse projeto é radicalizado, porém, quando Nietzsche desloca o programa genealógico do horizonte da cultura para o horizonte individual, como práxis autogenealógica, de modo que aquilo que em 1887 constituía uma investigação do conjunto da cultura é individualizado em cada um dos livros de 1888. Dessa maneira, as interlocuções que Nietzsche estabelece nos textos de 1888 - Sócrates, Platão, Wagner, Jesus, culturas, tradições filosóficas e morais, etc. -, exercem a função de lente de aumento por meio da qual Nietzsche enxerga melhor a si mesmo autogenealogicamente, bem como diferencia-se em relação a cada um desses interlocutores. ${ }^{21}$ As interlocuções culturais por meio do ideal ascético em GM são particularizadas por Nietzsche em cada uma das suas publicações de 1888. Como figura de pensamento, Nietzsche se autoencena em relação a Wagner, num embate entre $O$ caso Wagner e Nietzsche contra Wagner; como imoralista, fisiologista, com

19 Venho trabalhando essa hipótese já em outros textos, que igualmente já foram publicados, como por exemplo, na revista Estudos Nietzsche (2014), especificamente sobre Crepúsculo dos ídolos. Ainda sobre esse tema, cf. MÜLLER, E. Von der Umwerthung zur Autogenealogie. Die GötzenDämmerung im Kontext des Spätwerks. In: Gerhardt, V.; Reschke, R. (Hg.): Nietzsche im FilmProjektionen und Götzen-Dämmerung, Nietzscheforschung, 16, 2008, pp.141-149; STEGMAIER, W. "A crítica de Nietzsche da razão da sua vida: para uma interpretação de 0 anticristo e Ecce homo". In: As linhas fundamentais do pensamento de Nietzsche. Petrópolis: Vozes, 2013, pp.65-90.

20 Sobre a análise específica para cada uma dessas estruturas da cultura na terceira dissertação, cf. STEGMAIER, W. Nietzsches „Genealogie der Moral“, pp.173-204.

21 Cf. RUPSCHUS, A. Nietzsches Problem mit den Deutschen. Wagners Deutschtum und Nietzsches Philosophie (Monographien und Texte zur Nietzsche-Forschung). Berlin/Boston: Walter de Gruyter, 2013, especialmente o capítulo 3 intitulado "O problema de Nietzsche com os alemães, como problema consigo mesmo" (pp.74-148). 
a figura de pensamento "nós", enfim, Nietzsche se autoencena como instância argumentativa contrária à filosofia, à ciência, à política, no Crepúsculo dos ídolos; como autoencenação antagônica ao cristianismo na esfera da religião, Nietzsche escreve $O$ anticristo; e em Ecce homo, ao invés de falar autobiograficamente sobre sua vida, Nietzsche prefere se mostrar aos leitores: eis o homem!, tal como veremos mais adiante. 0 projeto genealógico da cultura de 1887 é, portanto, deslocado como práxis autogenealógica em intenso debate crítico com cada domínio da cultura: arte, filosofia, ciência, religião e moral; ou ainda, aquilo que em Paragenealogia da moral era pensado com vistas à cultura, nos textos de 1888 é realizado com vistas para si mesmo. ${ }^{22}$

\section{Formas de comunicabilidade do argumento autogenealógico}

Até esse ponto vim mencionando o termo encenação filosófica sem conferir a ele a devida sistematização teórica, algo que passo a fazê-lo a partir de agora. Grosso modo, a noção de encenação diz respeito às figuras de pensamento criadas por Nietzsche, por meio das quais ele exprime suas próprias reflexões e, inclusive, converte a si mesmo em instância argumentativa como figura de pensamento "Nietzsche". Certamente o tema exige um tratamento específico dado sua amplitude e complexidade, mas o instrumentalizo nesse texto apenas para indicar em que medida Nietzsche constrói uma estratégia argumentativa, baseada na construção específica das mais diversas encenações e autoencenações filosóficas, a fim de exprimir algo sobre si mesmo, numa tentativa de responder à pergunta: qual é a estratégia de comunicabilidade empregada por Nietzsche para abordar uma práxis autogenealógica? Ou ainda: quais as maneiras de comunicar uma subjetividade oriunda da práxis autogenealógica?

É preciso dizer inicialmente que o sentido de genealogia como crítica carrega uma peculiar estratégia de comunicabilidade. 0 argumento genealógico se caracteriza aqui tanto pelo seu aspecto apelativo, por meio do qual Nietzsche constrói encenações filosóficas, quanto heurístico-performático por meio do qual também objetiva exercer um efeito sobre o leitor. 0 objetivo dessa estratégia comunicativa é forçar a si próprio e a seu leitor a se colocarem no mesmo processo que é des-referencializado e criticado pela estratégia genealógica, ou seja, coagir a si e ao seu leitor a reconhecerem que não ocupam um lugar externo supostamente imune ao processo criticado, mas que são partes integrantes desse mesmo processo, inclusive objetivando uma autotransformação. ${ }^{23}$ A estratégia retórica do argumento genealógico encontrada nessa

22 Sobre esse ponto, cf. DETERING, H. Der Antichrist und der Gekreuzigte. Göttingen: Wallstein Verlag, 2010; MÜLLER, E. „Von der Umwerthung zur Autogenealogie. Die Götzen-Dämmerung im Kontext des Spätwerks“, pp.141-149; TONGEREN, P. „Vom ‘Arzt der Kultur' zum ‘Arzt und Kranken in einer Person' “. In: SOMMER, A. (Hrsg.), Nietzsche, Philosoph der Kultur(en)?, Berlin/New York: Walter de Gruyter, 2008,pp.11-29; SOMMER, Andreas U., Nietzsche-Kommentar: Der Fall Wagner, Götzen-Dämmerung. Berlin/Boston: Walter de Gruyter, 2012.

23 Sobre um aprofundado estudo dessa questão, cf. SAAR, M. Genealogie als Kritik, especialmente o capítulo 3.3 (pp.130-141). 
autoencenação possui, em termos bem gerais, uma quádrupla estrutura que podemos encontrar tanto em Para genealogia da moral, quanto nos textos de 1888 , por meio dos quais Nietzsche empreende sua autogenealogia:

1) Extemporaneidade: a estratégia crítica genealógica pressupõe a extemporaneidade, que por sua vez entendo como um distanciamento da situação na situação, ou seja, uma narrativa que implica estranhamento ou distanciamento, e que conecto ao conceito de extemporaneidade. Lembro aqui da referência do Prólogo à Segunda Consideração Extemporânea: "pois não saberia o que a filologia clássica na nossa época tomaria por sentido, a não ser atuar extemporaneamente - ou seja, contra a época e, com isso, na época e, talvez, em favor de uma época por vir". ${ }^{24} \mathrm{~A}$ crítica genealógica ajuda a tomar distância de padrões hegemônicos, ou lança luz aos domínios valorativos que se tornaram excessivamente evidentes. Lembremos de $O$ caso Wagner $(\mathrm{CW})$, pois é precisamente por meio dessa extemporaneidade que Nietzsche consegue fazer uma crítica e um “diagnóstico" do valor "da alma moderna"25. Ao ter sido infectado até a medula por Wagner, distancia-se criticamente para então, no interior da situação “da alma moderna”, operar a crítica não a Wagner propriamente, mas ao "caso" Wagner, como distanciamento de Wagner por meio do próprio Wagner;

2) Narrativa hiperbólica: a característica da performatividade textual da narrativa genealógica, se lembramos agora do próprio texto de Para genealogia da moral, possui o caráter hiperbólico, isto é, 2.1.) um exagero nas estilizações: personificações de tipos (Goethe, Emerson, Napoleão), 2.2) construção dos cenários hipotéticos (pré-história da moral - a moralização dos costumes - e inclusive a própria época), 2.3) dramatizações heurístico-retóricas (bando de bestas loiras, homem do ressentimento e igualmente o indivíduo soberano). Nesse caso, a narrativa crítica genealógica não é mera ornamentação de argumentos, mas a reunião de elementos textuais que atuam eles mesmos como argumentos. É precisamente dessa forma que Nietzsche, ao transformar a si mesmo em figura de pensamento, converte-se simultaneamente em instância argumentativa. É importante destacar que, em outros textos de 1888, essas mesmas estruturas são encontradas, inclusive em Ecce homo, quando Nietzsche transforma a si próprio em tipologia: "Por que sou tão inteligente”, “Por que sou tão sábio”, “Por que sou um destino”, “alegre mensageiro”, “imoralista”, “sem deus”, “ateu e anticristo”, etc.

3) Caráter apelativo: a narrativa genealógica produz certo "imperativo existencial" (termo emprestado de Martin Saar - Genealogie als Kritik) que, ao implodir ou delatar as autoevidências morais, desafia também o leitor a uma tomada de posição, objetivando o que se pode chamar tanto de autogenealogia como de transformação de si. A característica dessa narrativa genealógica, que certamente

24 Cons. Ext. II, HL, Prólogo; KSA 1, p.247.

25 CW Epílogo; KSA 6, p.53. 
pode ser denominada de heurístico-performática, faz o próprio leitor se reencontrar nas narrativas, mas de maneira distanciada, tomando a si próprio como objeto de reflexão, na medida em que o argumento exerce um caráter apelativo tanto para o próprio Nietzsche quanto ao leitor. Essa estrutura de comunicabilidade genealógica, especialmente esse terceiro aspecto a propósito do caráter apelativo, nos permite compreender que ele tem estreita conexão com a própria práxis autogenealógica.

4) Figurações: trata-se de narrativas críticas construídas sempre por meio de diferenciações em relação a uma teoria ou interlocutor, e que consiste em encenar as reflexões próprias ou inclusive a si mesmo. Certamente as figurações teóricas são as que mais bem exprimem a estratégia de comunicabilidade em uma práxis autogenealógica. Em primeiro lugar, as figurações são encenações que não são em si mesmas constitutivas, mas só sobrevivem se vigorarem como diferenciação em relação a teorias e interlocutores bem definidos, ou seja, figurações são entendidas não em si mesmas, mas sempre por meio de uma instância contraargumentativa. Por isso, trata-se de pensá-las não como teorias ${ }^{26}$, e sim como narrativas críticas. Para exemplificar, menciono o caso da encenação que Nietzsche faz da "vontade de poder" no aforismo 22, o penúltimo do primeiro capítulo de Para além de bem e mal. Renunciando à autoridade do autor, Nietzsche não fala em nome próprio, mas sim por meio da figuração que se autoencena como "velho filólogo" e que, ironicamente, "não consegue se livrar da maldade de colocar o dedo nas artes de interpretações ruins" ${ }^{27}$. Os interlocutores do aforismo são os "físicos" e sua "regularidade da natureza", que "existe apenas graças à sua interpretação e 'filologia' ruim". Encenada por meio da diferenciação em relação aos "físicos”, o "velho filólogo" cita no meio do aforismo a "vontade de poder" literalmente entre aspas, como se fosse um "intérprete" que apresentasse aos físicos uma "arte de interpretação oposta", e lesse na "mesma natureza e com vistas aos mesmos fenômenos, precisamente a inexorável imposição tirânica e impiedosa de reivindicações de poder". Chamo atenção aqui à peculiaridade da comunicação da vontade de poder no aforismo, isto é, não é Nietzsche que, em nome próprio, contrapõe sua vontade de poder, mas sim é o "velho filólogo" citando um filósofo de nome Nietzsche e sua vontade de poder, cuja citação, inclusive, é feita entre aspas. A narrativa crítica da vontade de poder, portanto, tanto é encenada por diferenciação em relação aos físicos e só tem sentido de ser se contextualizada em relação à "regularidade da natureza", bem como encenada por meio da figura de pensamento do "velho filólogo". ${ }^{28}$

26 Cf. STEGMAIER, W. Anti-Lehren. Szene und Lehre in Nietzsches „Also sprach Zarathustra“. In: GERHARDT, V. (Hg.). Also sprach Zarathustra, (Klassiker Auslegen). Berlin: Akademie Verlag, 2000, Pp.191-224.

27 ABM 22; KSA 5, p.37.

28 Para um estudo minucioso desse aforismo, cf. BORN, M. „Nietzsches rhetorische Inszenierung der Psychologie“. In: GEORG, J. ;ZITTEL, C. (Hrsg.). Nietzsches Philosophie des Unbewussten. Berlin/ 
As encenações filosóficas por meio de figurações não são comunicadas apenas para exprimir contradiscursos, mas também quando Nietzsche encena a si mesmo, como imoralista, ateu e anticristo, sem deus, impávidos, etc., cujo ponto de culminância parece ser sua última obra, Ecce homo, de modo que agora, para finalizar, arrisco uma interpretação a partir dessa lógica de argumentação que proponho.

Logo no primeiro aforismo do "Prólogo", ao indicar quão indispensável é dizer "quem eu sou", o autor Nietzsche alude ao fato de que seus contemporâneos nem o "viram, nem sequer o ouviram"29, ou seja, terminologias que lembram justamente um movimento de autoencenar-se (ver e ouvir). A autoencenação se justifica ainda mais, quando, ao final desse primeiro aforismo, Nietzsche se dirige aos seus interlocutores e escreve: “Ouçam-me! Pois eu sou assim e assado. Sobretudo não me confundam!”, isto é, a exigência de ouvi-lo como se o autor Nietzsche fosse iniciar a narrativa sobre um personagem, lendo-a diretamente aos ouvintes. Considero Ecce homo uma narrativa em que Nietzsche converte a si mesmo na mais extrema instância argumentativa. Minha hipótese é que Nietzsche constrói uma narrativa mobilizando cenários, situações, histórias, debates e, especialmente, um personagem que em nenhum momento recebe um nome em específico. Isso significa que a narrativa não é da própria vida do filósofo Nietzsche, numa suposta tentativa de falar de si mesmo justificando biograficamente suas próprias condições de vida, mas antes, uma narrativa crítica que opera por mostração, de modo a renunciar a dizer "minha vida" - em franca oposição e "uma radical alternativa à biografia de Wagner, Mein Leben"30_, optando muito mais por mostrar seu personagem finalmente narrado aos seus leitores: Ecce homo.

Nesse caso, há um narrador Nietzsche que encena o personagem narrado e finalmente o apresenta aos endereçados da narrativa, mostrando-o aos leitores. Em termos específicos, é como se o homem Nietzsche narrasse um personagem que, sem especificar quem seja esse personagem, ou mesmo qual o seu nome, prefere ao final simplesmente mostrá-lo aos seus interlocutores - daí o título do livro que alude ao momento em que Pilatos mostra Jesus à multidão e diz "ecce homo"-, perguntando aos leitores: “Vocês me compreenderam?”. É preciso enfatizar que essa pergunta é repetida por três vezes precisamente nos três últimos aforismos de Ecce homo. Apráxis interrogativa que explicamos no início nunca abandona as estratégias de Nietzsche, especialmente para enfatizar a materialidade da linguagem que, nesse caso, força o leitor, performaticamente, a se posicionar sobre o que o próprio Nietzsche narra. No caso da narrativa em Ecce homo, a práxis interrogativa apenas indica que a filosofia de Nietzsche é uma filosofia que culmina com a necessária presença do leitor. Isso

Boston: Walter de Gruyter, 2012, pp.197-206.

29 EH, Prólogo 1; KSA 6, p.257.

30 Cf. GÖRNER, R. Wenn Götzen dämmern. Formen ästhetischen Denkens bei Nietzsche. Göttingen: Vandenhoeck \& Ruprecht, 2008, p.111. 
significa que é o leitor que efetivamente tem de dizer quem é o personagem da narrativa. Mais ou menos como ao final de uma peça teatral em que o diretor pergunta aos espectadores: o que acharam da encenação? Nietzsche intitula o livro 'ecce homo' sem nomear o personagem, sem dizer quem é biograficamente, mas relegando ao leitor, por meio das três últimas perguntas do livro - 'vocês me compreenderam?' -, a responsabilidade de finalmente nomear o personagem da narrativa. ${ }^{31} \mathrm{Em}$ suma: com Ecce homo, Nietzsche radicaliza a construção narrativa, cuja encenação é a construção de um personagem apresentado ao final do livro aos interlocutores, de modo que, em última instância, é o leitor que decide quem é o personagem, restando ao homem Nietzsche apenas mostrá-lo aos leitores: "ecce homo"!

Como se vê, embora Nietzsche nunca tenha empregado o termo autogenealogia, seu uso teórico pode ser justificado por meio tanto da instância formal quanto da semântica do argumento, tal como denomino. Se genealogia em Nietzsche é genealogia da moral, as margens de atuação do conceito de genealogia podem ser ampliadas para outros domínios da cultura e inclusive no domínio da subjetividade como exercício autogenealógico, assim que compreendemos a forma e o conteúdo da estrutura básica da genealogia, de modo que possamos testar sua validade também fora do âmbito da moralidade. Assim, ampliamos não apenas a compreensão do conceito, mas inclusive a própria filosofia de Nietzsche. E se ele escreveu sobre si mesmo que alguns nascem "póstumos", é justamente porque sua filosofia ainda se apresenta como inesgotável. Um pensamento que culmina com a presença do leitor, nós mesmos nesse caso, é uma filosofia que não apenas continuamente atualiza uma filosofia, mas que também a torna ininterruptamente extemporânea.

\section{Referências}

BENNE, C.; MÜLLER, E. Ohnmacht des Subjekts - Macht der Persönlichkeit. Basel: Schwabe Verlag, 2014.

BORN, M. „Nietzsches rhetorische Inszenierung der Psychologie“. In: GEORG, J.; ZITTEL, C. (Hrsg.). Nietzsches Philosophie des Unbewussten. Berlin/Boston: Walter de Gruyter, 2012, pp.197-206.

DETERING, H. Der Antichrist und der Gekreuzigte. Göttingen: Wallstein Verlag, 2010.

GÖRNER, R. Wenn Götzen dämmern. Formen ästhetischen Denkens bei Nietzsche. Göttingen: Vandenhoeck\& Ruprecht, 2008.

KAULBACH, F. Nietzsches Idee einer Experimentalphilosophie. Köhl/Wien: Böhlau, 1980.

LOSSI, A. „Philosophie als Selbstgestaltung? Umwertung und Selbstverständnis im Ausgang von Nietzsches von den ,Vorurtheilen der Philosophen" in Jenseits von Gut und Böse“.

31 Sobre a noção de encenação filosófica em inúmeras instâncias da filosofia de Nietzsche, inclusive Ecce homo, cf. BENNE, C.; MÜLLER, E. (Hg.). Ohnmacht des Subjekts - Macht der Persönlichkeit. Basel: Schwabe Verlag, 2014. 
In: BORN, M.;PICHLER, A. (Hrsg.). Texturen des Denkens. Nietzsches Inszenierung der Philosophie in Jenseits von Gut und Böse. Berlin/Boston: Walter de Gruyter, 2013, pp.107122.

MÜLLER, E.Von der Umwerthung zur Autogenealogie. Die Götzen-Dämmerung im Kontext des Spätwerks. In: GERHARDT, V.; RESCHKE, R. (Hg.): Nietzsche im Film-Projektionen und Götzen-Dämmerung, Nietzscheforschung, 16, 2008, pp.141-149.

NIETZSCHE, F. Sämtliche Werke. Kritische Studienausgabe in 15 Bänden. (KSA) Hrsg. Giorgio Colli und MazzinoMontinari. Berlin/New York: DTV \& Walter de Gruyter, 1999.

RUPSCHUS, A. Nietzsches Problem mit den Deutschen. Wagners Deutschtum und Nietzsches Philosophie. (Monographien und Texte zur Nietzsche-Forschung). Berlin/Boston: Walter de Gruyter, 2013.

SAAR, M. Genealogie als Kritik. Geschichte und Theorie des Subjekts nach Nietzsche und Foucault. Frankfurt/New York: Campus Verlag, 2007.

SOMMER, A. Nietzsche-Kommentar. Der Fall Wagner, Götzen-Dämmerung. Berlin/Boston: Walter de Gruyter, 2012.

STEGMAIER, W. Nietzsches „Genealogie der Moral“, Darmstadt: WGB, 1994.

•,Anti-Lehren. Szene und Lehre in Nietzsches ,Also sprach Zarathustra““. In: GERHARDT, V. (Hg.). Also sprach Zarathustra, (Klassiker Auslegen). Berlin: Akademie Verlag, 2000, pp.191-224. Nietzsches Befreiung der Philosophie. Berlin/Boston: Walter de Gruyter, 2012. - "A crítica de Nietzsche da razão da sua vida: para uma interpretação de $O$ anticristo e Ecce homo". In: __ As linhas fundamentais do pensamento de Nietzsche. Petrópolis: Vozes, 2013, pp.65-90.

TONGEREN, P. „Vom ‘Arzt der Kultur’ zum ‘Arzt und Kranken in einer Person’“. In: SOMMER, A. (Hrsg.). Nietzsche, Philosoph der Kultur(en)?, Berlin/New York: Walter de Gruyter, 2008, pp.11-29.

A moral da crítica de Nietzsche à moral. Estudo sobre "Para além de bem e mal”. Tradução de Jorge L. Viesenteiner. Curitiba: Champagnat, 2012. 